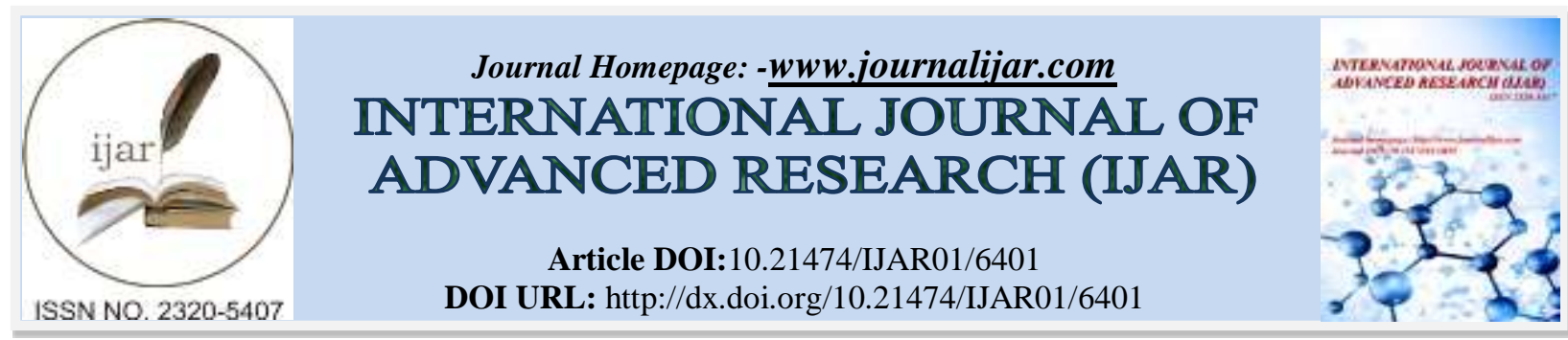

RESEARCH ARTICLE

\title{
THE EFFECT OF DOUBLE J STENT ON THE EFFICACY OF EXTRACORPOREAL SHOCK WAVE LITHOTRIPSY IN THE TREATMENT OF URETERAL STONES.
}

\author{
Venugopal A V ${ }^{1}$, Shanmugha Das $\mathrm{KV}^{2}$, Bhavish $\mathrm{VS}^{3}$ and Felix Cardoza ${ }^{4}$. \\ 1. Additional Professor, Department of Urology, Govt Medical College, Calicut, Kerala. \\ 2. Additional Professor, Department of Urology, Govt Medical College, Calicut, Kerala. \\ 3. Senior Resident, Department of Urology, Govt Medical College, Calicut, Kerala. \\ 4. Professor \& HOD, Department of Urology, Govt Medical College, Calicut, Kerala.
}

\section{Manuscript Info}

Manuscript History

Received: 01 December 2017

Final Accepted: 03 January 2018

Published: February 2018

Key words:-

ESWL; Ureteral stones; DJ stent, Efficacy.

\section{Abstract}

Objective: To evaluate the effect of double J stent on the

efficacy of extracorporeal shock wave lithotripsy in the treatment of ureteral stones.

Patients and methods: Open labelled prospective audit of patients with solitary ureteric calculi receiving ESWL in a single centre was performed during May 2015 to July 2017.The study group consisted of 176 ureteric stone patients who were treated with ESWL. In 68 cases, treatment was preceded by ureteric stent insertion. Success was defined as complete stone clearance in post procedure X ray KUB imaging after 2 weeks. Demographic data of patients and stone characteristics were correlated with ESWL outcome. Logistic regression analysis was applied to evaluate the hypothesis of an interaction between stone size and the presence of a D J stent.

Results: The mean age of patients were 39.68 years (range 21-68), $70.45 \%$ $(124 / 176)$ of patients were males. Mean stone size was $13.2 \mathrm{~mm}$. The overall success rate with ESWL is $68.18 \%$. Treatment was more effective for smaller $(p=0.162)$ and more proximally located stones $(p=0.025)$. A DJ stent in situ at the time of ESWL reduced the success rate for stones with size more than10 $\mathrm{mm}(\mathrm{p}=0.032)$.

Conclusions: Our study demonstrated that the presence of double $\mathrm{J}$ stent reduces the success rate of ESWL treatment when the stone size is more than $10 \mathrm{~mm}$ in size.

Copy Right, IJAR, 2018,. All rights reserved.

\section{Introduction:-}

Urolithiasis is a major clinical and economic burden for health care systems. It is estimated that up to $13 \%$ of men and $7 \%$ of women develop urolithiasis in their lifetime ${ }^{1}$. Several prognostic factors determining the success of ESWL treatment of ureteric stones have been studied. These include the stone site, size, crystal type, degree of obstruction, stone impaction and function of the renal unit ${ }^{2,3}$. Studies of the effect of the presence of a double $\mathbf{J}$ stent on the ESWL success rate have given conflicting results.

The objective of this prospective study was to assess the effect of the presence of a double $\mathrm{J}$ stent on the treatment of ureteral stones by ESWL.

Corresponding Author:- Shanmugha Das. K. V. 


\section{Patients and methods:-}

The data from all patients undergoing extracorporeal shock wave lithotripsy for ureteric calculus in the department of urology at Government Medical College, Kozhikode were reviewed over a two year period from August 2015 to July 2017.

Inclusion criteria:-

- $\quad$ Radio opaque stone (stones visualized in X-ray KUB )

- Solitary stone

- $\quad$ Stone size between 8-20 mm

\section{Exclusion criteria:-}

- Multiple stones

- Stone density more than $1200 \mathrm{HU}$

- History of previous interventions for ureteric stone

- Non availability of post-treatment imaging

- Lack of documents for follow up

After these criteria were met, 176 patients were available for inclusion in this study. The patients were divided into two groups for study analysis: group 1, those in whom a double J stent had been inserted ('stented') and group 2 comprising of patients without a double J stent ('non-stented'). Double J stents were inserted, in patients with renal colic complicated with obstructive pyelonephritis, in acute renal insufficiency, and in severe colic not relieved by analgesics. To define stone site the ureter was divided into three areas (i) upper ureter: between PUJ and upper sacroiliac joint (ii) mid ureter: between upper and lower sacro iliac joint and (iii)lower ureter: distal to lower sacroiliac joint

All 176 patients were evaluated with pre ESWL X ray KUB to assess the opacity, size, and location of the stone in the ureter. The density of each stone was assessed by a non contrast CT scan. The age, gender and body mass index (BMI) of each patient, along with the side of the stone, its size and density; the tolerance of the procedure by the patient; and the number, frequency and power of the ESWL shots, were all recorded.

The ESWL sessions were conducted by using the same lithotripter (DIREX Compact XL ${ }^{\circledR}$ lithotripter) under fluoroscopic guidance, with local anaesthesia (Lignocaine +Pirlocaine cream) and iv sedation (InjNalbuphine) . Post-treatment imaging and patient records were reviewed to determine the outcome of each patient. In patients who had received a double $\mathbf{J}$ stent, the ESWL was performed at least 3 weeks after the stent placement upto a maximum period of four weeks. ESWL was not done in cases of acute urinary infection, acute pain, or acute obstructive renal insufficiency.

Success was defined as near complete resolution of the ureteric stone with single session of ESWL treatment alone. Imaging of all patients by X-ray KUB was done two weeks after treatment. Treatment was considered to be successful if the patient was stone free after the procedure, or had a residual stone of size less than or equal to 4 $\mathrm{mm}$. If the stone was either unchanged in size or more than $4 \mathrm{~mm}$, treatment was considered to have failed. Failure was defined as incomplete clearance of the ureteric stone requiring secondary procedures. Those that failed lithotripsy were listed for ureteroscopy and stone fragmentation.

\section{Statistical analysis:-}

The Student $t$ test was used to analyze patient's characteristics. The chi-square test was used to compare group 1 with group 2. Bivariate analysis evaluated the results in terms of calculus size. Logistic regression analysis was applied to evaluate the hypothesis of an interaction between stone size and the presence of a DJ stent. The results were given with their odds ratio (OR) and $95 \%$ confidence interval $\left(\mathrm{CI}_{95 \%}\right)$. Results were considered significant when $p<0.05$.

\section{Demographic details:-}

Patient characteristics are shown in Table 1. Of the 176 patients included in the statistical analysis, 68 were in group 1 and 108 in group 2. The mean age was 39.68 years (range 21-68years) There was no statistical difference between mean ages of those patients that received successful lithotripsy (mean age 37.8 years) from those that failed treatment (mean age 39.1 years). Of the 176 patients, $124(70.45 \%)$ were male and $52(29.55 \%)$ were female. There 
was no statistically different rate of success for male $(69.1 \%)$ compared to female $(68.3 \%)$. The mean stone size was $13.2 \mathrm{~mm}$. Groups 1 and 2 were comparable in terms of age, BMI, size and density of stones, and in number, power, and frequency of ESWL shots. All ESWL sessions were well tolerated by the patients.

Table 1:-Patient characteristics

\begin{tabular}{|l|l|l|l|}
\hline $\begin{array}{l}\text { Total } \\
\mathbf{n}=\mathbf{1 7 6}\end{array}$ & $\begin{array}{l}\text { Group 1 } \\
\text { (DJ stent -Present) }\end{array}$ & $\begin{array}{l}\text { Group 2 } \\
\text { (DJ stent -Absent) }\end{array}$ & p value \\
\hline Patients & $\mathrm{n}=68$ & $\mathrm{n}=108$ & \\
\hline Male & $44(64.7 \%)$ & $80(74 \%)$ & \\
\hline Female & $24(35.3 \%)$ & $28(26 \%)$ & \\
\hline Age & 40.14 & 36.68 & 0.634 \\
\hline (years) & $(+18.3)$ & $(+18.5)$ & \\
\hline BMI & 28.8 & 27.6 & 0.326 \\
\hline Kg/M 2$)$ & $(+4.6)$ & $(+4.3)$ & \\
\hline Stone side - Right & $32(47 \%)$ & $48(44.5 \%)$ & \\
\hline Left & $36(53 \%)$ & $60(55.5 \%)$ & 0.162 \\
\hline Size & 9.8 & 10.6 & $(+2.5)$ \\
\hline (mm) & $(+4.7)$ & 861 & 0.1 \\
\hline Density (HU) & 958 & $(+216)$ & \\
\hline & $(+231)$ & 2885 & 0.904 \\
\hline ESWL-No shocks & 2890 & $(+430)$ & \\
\hline & $(+450)$ & & \\
\hline ESWL Voltage & $5-30 \mathrm{KV}$ & & \\
\hline ESWL Frequency & $80-120$ shocks / minute & \\
\hline
\end{tabular}

Fig 1:-Stone density in relation to stone size

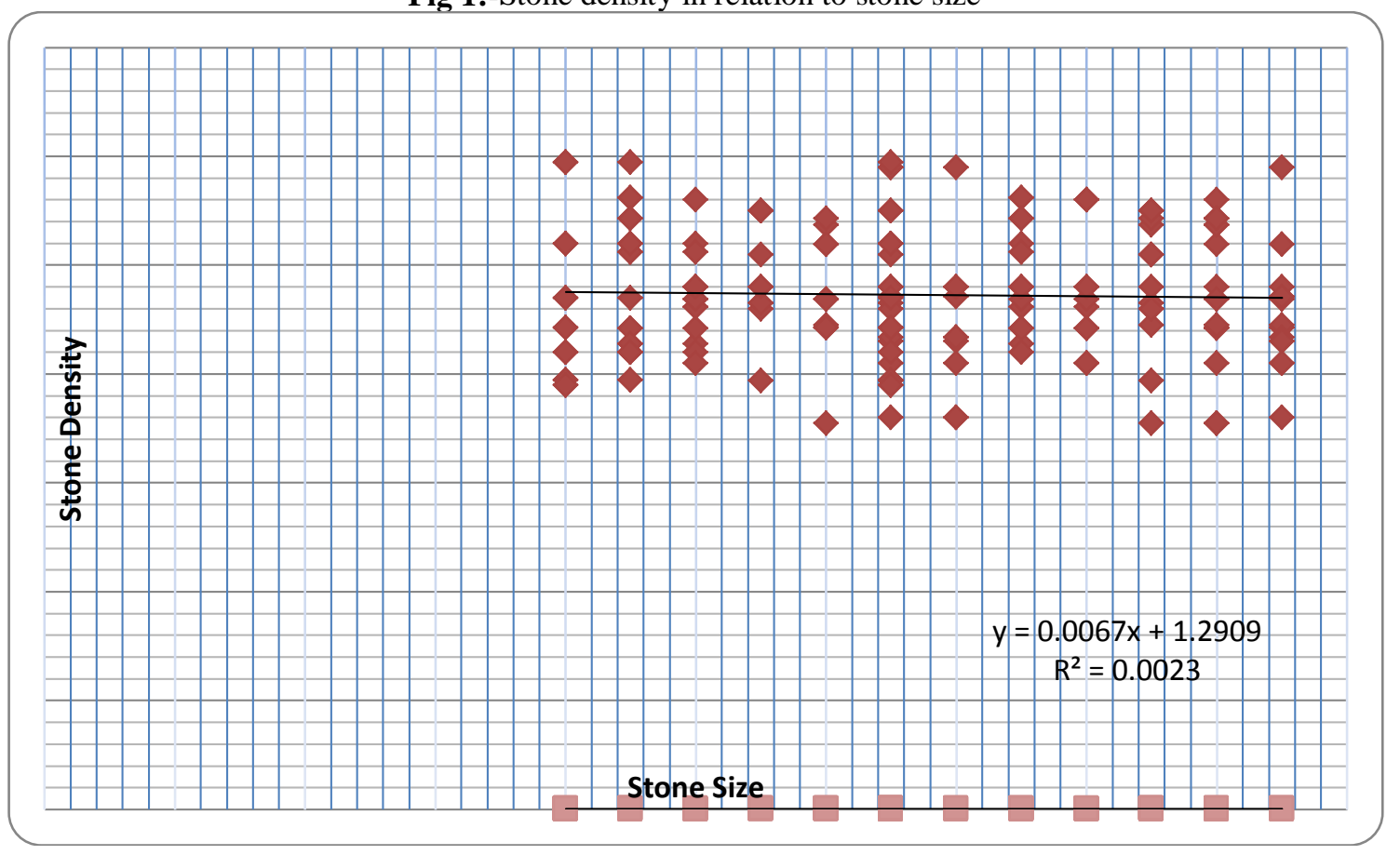

Analysis of outcome:-

The overall success rate was $68.18 \%(\mathrm{n}=120 / 176)$. The success rate was higher in group $2(81.52 \% \mathrm{vs} .47 .1 \%)$; $\mathrm{OR}=4.94 ; \mathrm{CI}{ }_{95 \%}\{1.26-19.24\} ; p$ value $\left.=0.017\right)$ (Table 2). There was no significant difference between the success in two groups for stones $\leq 10 \mathrm{~mm}\left(84.2 \% \mathrm{vs} .75 \%\right.$ in groups 2 and 1 , respectively; $\mathrm{OR}=1.77 ; \mathrm{CI}_{95 \%}\{0.24-$ $13.5\} ; p=0.575)$. For stones $>10 \mathrm{~mm}$, the success rate was lower in group $1(75 \%$ vs. 22,2\%; OR $=10.5$; 
$\mathrm{CI}_{95 \%}\{1.115-98.9\} ; p=0.03$ ) (Table 3). Logistic regression analysis showed a higher failure rate when a double $\mathrm{J}$ stent was associated with a stone $>10 \mathrm{~mm}\left(\mathrm{OR}=2.82: \mathrm{CI}_{95 \%}\{1.088-7.307\} ; p=0.033\right)$.

Table 2:-Success and failure rates in group1 and 2

\begin{tabular}{|l|l|l|}
\hline & Success & Failure \\
\hline Group 1 (DJ Stent + ) & $47.05 \%$ & $52.95 \%$ \\
\hline $\mathrm{n}=68$ & $(\mathrm{n}=32)$ & $(\mathrm{n}=36)$ \\
\hline Group 2 (no DJ Stent) & $81.48 \%$ & $18.52 \%$ \\
\hline $\mathrm{n}=108$ & $(\mathrm{n}=88)$ & $(\mathrm{n}=20)$ \\
\hline $\mathrm{p}$ value & 0.017 & \\
\hline
\end{tabular}

Table 3:-Success rates in group 1 and 2 according to stone size

\begin{tabular}{|l|l|l|}
\hline & Size $\leq \mathbf{1 0} \mathbf{~ m m}$ & Size $>\mathbf{1 0} \mathbf{~ m m}$ \\
\hline Group 1 (DJ Stent +$)$ & $75 \%$ & $22.2 \%$ \\
\hline $\mathrm{n}=68$ & $(\mathrm{n}=24 / 32)$ & $(\mathrm{n}=8 / 36)$ \\
\hline Group 2 (no DJ stent) & $84.2 \%$ & $75 \%$ \\
\hline $\mathrm{n}=108$ & $(\mathrm{n}=64 / 76)$ & $(\mathrm{n}=24 / 32)$ \\
\hline $\mathrm{P}$ & 0.564 & 0.032 \\
\hline
\end{tabular}

Table 4:-Success rates in group 1 and 2 according to stone location

\begin{tabular}{|c|c|c|c|c|c|}
\hline & \multicolumn{2}{|c|}{ Success rate (\%) } & \multicolumn{2}{|c|}{ Failure rate (\%) } & \multirow[t]{2}{*}{ Total Success rate $(\%)$} \\
\hline & No stent & Stent + & No stent & Stent + & \\
\hline $\begin{array}{l}\text { Upper } \\
\text { ureter }\end{array}$ & $70(81.39 \%)$ & $16(18.61 \%)$ & $10(45.45 \%)$ & $12(54.55 \%)$ & $\begin{array}{l}86 / 108(79.62 \%) \\
p=(0.025)\end{array}$ \\
\hline $\begin{array}{l}\text { Middle } \\
\text { ureter }\end{array}$ & $8(57.14 \%)$ & $6(42.86 \%)$ & $6(30 \%)$ & $14(70 \%)$ & $\begin{array}{l}14 / 34(41.18 \%) \\
p=(0.48)\end{array}$ \\
\hline $\begin{array}{l}\text { Lower } \\
\text { ureter }\end{array}$ & $10(50 \%)$ & $10(50 \%)$ & $4(28.57 \%)$ & $10(71.43 \%)$ & $\begin{array}{l}20 / 34(58.82 \%) \\
p=(0.19)\end{array}$ \\
\hline & $88(73.33 \%)$ & $32(26.67 \%)$ & $20(35.71 \%)$ & $36(64.29 \%)$ & $120 / 176(68.18 \%)$ \\
\hline
\end{tabular}

\section{Discussion:-}

In the study reported here, the overall success rate of ESWL was $68.2 \%$, with a success rate of $81.5 \%$ for those patients who had not been stented with a double J stent. In our study, the treatment by ESWL of ureteral stones was impaired by the presence of a double $\mathrm{J}$ stent, and this was even more significant when the stone was more than 10 $\mathrm{mm}$ in size.

In contrast to this study, a study by Mobley et al showed that the presence of a ureteral stent did not affect the success rate of ESWL ${ }^{4}$, irrespective of stone location in the ureter. However, in that large retrospective study, only $19.3 \%$ of the patients had been stented before treatment. Similarly, when compared with the study by Middela et al, no significant difference was found between the outcome for patients with stones treated by ESWL irrespective of presence of a stent ${ }^{5}$,but in that series multiple sessions were needed in most cases (52\% with two sessions, $30 \%$ with more than three).

Pace et $\mathrm{al}^{6}$ estimated that the presence of a ureteral stent caused a $12 \%$ reduction of the stone-free success rate $(p=$ 0.001), which was comparable with our study in which success rate was $81.48 \%$ without DJ stent and $47.05 \%$ with DJ stent insitu (p-0.017). ESWL failure rate in stented group is slightly higher in this study. This can be attributed to the fact that, stenting was done in relatively bigger and impacted stones, compared with the non stented group, hence resulting in reduced stone clearance. Lingeman JE et al,other authors ${ }^{7,8}$ have also reported similar results, confirming that the presence of a double $J$ stent conferred no advantage on the results of ESWL or, in fact, impaired its success rate.

Several theories have been proposed to explain the effect of the presence of a double $\mathrm{J}$ stent on the efficacy of ESWL in fragmenting ureteral stones. In order to exert the maximum effect on the stone, the shock waves must impinge on a stone surrounded by liquid. Thus the negative effect of the double J stent on ESWL may be attributable to two mechanisms: first, the double $\mathrm{J}$ stent may absorb some of the energy created by the shock waves, reducing 
their effect on the stones ${ }^{9}$; second, the presence of such a stent may cause ureteral edema, hindering the passage of the stone fragments ${ }^{10,11,12}$.

Stone size is another important factor that influences the efficacy of ESWL irrespective of presence or absence of DJ stent: Park et $\mathrm{al}^{13}$; and a meta-analysis ${ }^{14}$; reported in 2007 that the success rate of ESWL falls significantly, from $86 \%$ to $67.5 \%$, with stones more than $10 \mathrm{~mm}$ in size, this was comparable with this study, in which success rate fell from $81.48 \%$ to $47.05 \%$ with stone of size more than $10 \mathrm{~mm}$ in size.

Location of stones in the ureter is another important factor that determines the effectiveness of ESWL irrespective of presence or absence of DJ stent. Proximal ureter has got highest success rates, followed by lower ureter stones, and least in case of mid ureter stones. This study also shows similar results with a success rate of $79.6 \%$ for upper ureter stones, $58.82 \%$ for lower ureter stones and $41.18 \%$ for middle ureter stones respectively ${ }^{14}$.

In the study reported here, ESWL was found to be less effective in fragmenting ureteral stones with size more than $10 \mathrm{~mm}$ in those patients in whom a double $\mathrm{J}$ stent had been inserted with a reduction in success rate by $52.8 \%$ in comparison with non stented group. This can be attributed to the fact that, in this study pre ESWL stenting was done only in cases of renal colic complicated with pyelonephritis or acute kidney injury, in these cases stones are usually impacted with ureter thereby decreasing the stone clearance by ESWL procedure.

\section{Conclusion:-}

In conclusion, the results of this study indicate that the presence of a double $\mathbf{J}$ stent, in patients with ureteral stones, impairs the efficacy of ESWL in their treatment. This effect is significant for stones with size more than $10 \mathrm{~mm}$.

\section{Limitations:-}

We acknowledge that this study also has limitations: the small number of patients and relatively less patients in stented arm are common constraints in such studies. The stone density was slightly higher in the stented group (956 $\mathrm{HU}$, vs $861 \mathrm{HU})$; however, this difference was not statistically significant. Hence we suggest adequately powered prospective studies to draw a clear cut effect of DJ stent in ESWL for ureteric calculus.

\section{Sources of funding:- Nil}

\section{Conflict of interest statement:-}

The authors declare that there are no conflicts of interest.

Acknowledgement:- We are highly indebted to out patients for consenting and cooperating for this study.

Contribution Details:- All authors have participated sufficiently in the intellectual content, conception and design of this study as well as in the writing of the manuscript.

\section{References:-}

1. Stamatelou KK, Francis ME, Jones CA, Nyberg LM, Curhan GC. Time trends in reported prevalence of kidneystones in the United States: 1976-1994. Kidney Int2003; 63(5):1817-23.

2. Salman M, Al-Ansari AA, Talib RA, El-Malik el-F, Al-BozaomIA, Shokeir AA. Prediction of success of extracorporealshock wave lithotripsy in the treatment of ureteric stones.IntUrolNephrol 2007; 39(1):85-9.

3. Azm T, Higazy H. Effect of diuresis on extracorporeal shockwavelithotripsy treatment of ureteric calculi. Scand J UrolNephrol 2002; 36(3):209-12.

4. Mobley TB, Myers DA, Jenkins JM, Grine WB, Jordan WR. Effects of stents on lithotripsy of ureteral calculi: treatment results with 18,825 calculi using the Lithostarlithotriptor J Urol 1994;152:53-56.

5. Middela S, Papadopoulos G, Srirangam S, Rao P. Extracorporeal shock wave lithotripsy for ureteral stones: do decompression tubes matter? Urology 2010; 76:821-825.

6. Pace KT, Weir MJ, Tariq N, Honey RJ. Low success rate of repeat shock wave lithotripsy for ureteral stones after failed initial treatment. J Urol 2000; 164:1905-1907.

7. Chang S, Kuo HC, Hsu T. Extracorporeal shock wave lithotripsy for obstructed proximal ureteral stones. A prospective randomized study comparing in situ, stent bypass and below stone catheter with irrigation strategies. EurUrol 1993; 24:177-184. 
8. Musa AA. Use of double-J stents prior to extracorporeal shock wave lithotripsy is not beneficial: results of a prospective randomized study. IntUrolNephrol. 2008; 40:19-22.

9. Ghoneim IA, El-Ghoneimy MN, El-Naggar AE, Hammoud KM, El-Gammal MY, Morsi AA. Extracorporeal shock wave lithotripsy in impacted upper ureteral stones: a prospective randomized comparison between stented and non-stented techniques. Urology. 2010; 75:45-50.

10. Singh I, Gupta NP, Hemal AK, Dogra PN, Ansari MS, Seth A, Aron M. Impact of power index, hydroureteronephrosis, stone size, and composition on the efficacy of in situ boosted ESWL for primary proximal ureteral calculi. Urology. 2001; 58:16-22.

11. Ryan PC, Lennon GM, McLean PA, Fitzpatrick JM. The effects of acute and chronic JJ stent placement on upper urinary tract motility and calculus transit. Br J Urol. 1994; 74:434-439.

12. Joshi HB, Obadeyi OO, Rao PN. A comparative analysis of nephrostomy, JJ stent and urgent in situ extracorporeal shock wave lithotripsy for obstructing ureteric stones. Br J Urol. 1999; 84:264-269.

13. Park H, Park M, Park T. Two-year experience with ureteral stones: extracorporeal shockwave lithotripsy v ureteroscopic manipulation. J Endourol 1998; 12:501-504.

14. Kijvikai K, Haleblian GE, Preminger GM, de la Rosette J. Shock wave lithotripsy or ureteroscopy for the management of proximal ureteral calculi: an old discussion revisited. J Urol. 2007; 178:1157-1163. 